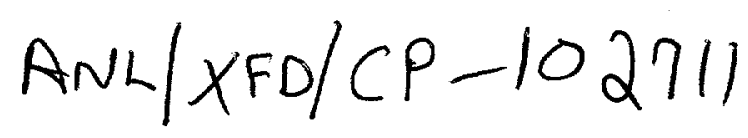

\title{
Development and Applications of Rectangular Box-Type Explosively Bonded Structures for High-heat-load Beamline Components
}

\author{
D. Shu ${ }^{\mathrm{a}}$, J. Chang ${ }^{\mathrm{a}}$,T. M. Kuzay ${ }^{\mathrm{a}}$, and D. G. Brasher ${ }^{\mathrm{b}}$ \\ advanced Photon Source, Argonne Vational Laboratory. \\ Argonne, Illinois 60439. U. S. A. \\ ${ }^{b}$ High Energy Metals, Inc., \\ 419 Haines Place, Port Townsend, Washington 98368, U. S. A.
}

\begin{abstract}
Explosive bonding technology is a good choice to join dissimilar materials, such as $304 \mathrm{~L}$ stainless steel and GlidCop AL-15, and is used extensively in making the Advanced Photon Source (APS) high-heat-load beamline and front-end components. It is a bonding method in which the controlled energy of a detonating explosive is used to create a metallurgical bond between two or more similar or dissimilar materials.

In recent years, special explosive bonding units with rectangular box-type joints were developed for the APS new high-heat-load beamline components. Based on this new technique, the box form of the component could be built in two halves first, then welded together. Therefore, beamline designers have more freedom to optimize the cooling surface geometry.

In this paper, we will present several different high-heat-load component designs using box-type explosive bonding units for APS undulator front ends and beamlines.
\end{abstract}

Keywords: explosive bonding, explosive weld, high-heat-load component, ultrahigh vacuum.

\section{Introduction}

GlidCop $^{\mathrm{TM}}$ is an aluminum oxide, dispersion-strengthened copper alloy [1]. It has been a material of choice for many high-heat-load components because of its good thermal conductivity and high yield strength. But, it is a material that is difficult to weld or braze using traditional methods. Explosive bonding provides a way to produce a quality, UHV-tight bonding between GlidCop and stainless steel.

Explosive bonding is a bonding method in which the controlled energy of a detonating explosive is used to create a metallurgical bonding between two or more similar or dissimilar materials. The process of explosive bonding (also called welding) has been well understood for over forty years, and there have been many excellent reviews on the intricacies involved [2-4].

Since 1991, a number of explosively bonded joints have been designed for high-heatload ultrahigh-vacuum (UHV) compatible components in the APS beamlines and its front ends [5]. A series of standardized explosive bonded joint units has also been designed and tested, such as oxygen-free copper (OFHC) to stainless-steel vacuum joints for slits and shutters, GlidCop to stainless-steel vacuum joints for fixed masks. and GlidCop to OFHC thermal and mechanical joints for shutter face-plates, etc.

In 1995, based on the experiences obtained from APS specially designed OFHC to stainless-steel UHV joint with a rectangular shape, we have developed a first prototype of a stainless-steel to GlidCop explosively bonded box-type UHV leak-tight structure. Later, 


\section{DISCLAIMER}

This report was prepared as an account of work sponsored by an agency of the United States Government. Neither the United States Government nor any agency thereof, nor any of their employees, make any warranty, express or implied, or assumes any legal liability or responsibility for the accuracy, completeness, or usefuiness of any information, apparatus, product, or process disclosed, or represents that its use would not infringe privately owned rights. Reference herein to any specific commercial product, process, or service by trade name, trademark, manufacturer, or otherwise does not necessarily constitute or imply its endorsement, recommendation, or favoring by the United States Government or any agency thereof. The views and opinions of authors expressed herein do not necessarily state or reflect those of the United States Government or any agency thereof. 


\section{DISCLAIMER}

Portions of this document may be illegible in electronic image products. Images are produced from the best available original document. 
this structure was successfully applied to high-heat-load photon shutter design for the SPring-8 project in Japan [6]. In recent years, more applications have been developed at the APS using this unique bonded structure, and we have worked to optimize the invacuum cooling surface geometry.

In this paper. beginning with a brief description of the process of box-type explosive bonding, we then present the design of the bonding unit applied to the APS front-end and beamline components.

\section{Box-type explosive bonding for UHV components}

The explosive bonding process is considered a solid-state welding process and uses controlled explosive energy to force two or more metals together at high pressures. The matallurgical joining occurs when the clad metal is driven down into the base metal by the explosive energy. The force of the explosion sets up an angular collision, which produces ejected plasma as shown in fig. 1. The plasma jet acts to remove impurities from both metals' surfaces in front of the collision point, leaving behind clean metal for joining. The pressures at the collision point, which can be from 100,000 - 600,000 psi, are enough to squeeze the metals into behaving like viscous fluids. The fluid-like behavior is responsible for creating the wave pattern bond line in an explosive bond as shown in fig. 2.

The obvious benefit of this process is the joining of metallurgically incompatible systems, such as GlidCop and stainless steels. Because any conventional joining method that uses heat during the bonding or welding of incompatible metals may cause brittle intermetallic compounds to form.

Fig. 3a shows a typical rectangular box-type explosively bonded unit for one half of an APS photon shutter consisting of two materials. The base material is GlidCop AL-15 with a size of $387 \mathrm{~mm}(\mathrm{~L}) \times 60.5 \mathrm{~mm}(\mathrm{~W}) \times 41 \mathrm{~mm}(\mathrm{H})$. The four 6.35 -mm-thick side walls are made from $304 \mathrm{~L}$ stainless steel and are explosively bonded with the base material to form a UHV leak-tight structure.

In order to produce a quality box-type bonding, the variables that affect the bonding formation must be controlled. There are three major technical challenges to perform such a good quality box-type bonding unit.

- Precise metal thinning estimation is very important for controlling the product's final dimension tolerances.

- A larger explosive load or interface spacing causes a larger collision angle and a more turbulent interface. It may be desirable to attain a wavy interface to increase the shear strength of a transition joint. But on the other hand, the box-type structure needs good bond-line linearity. Thus, optimized wavy bond control is critical in the box-type bonding operation.

- To achieve a UHV leak-tight joint, corner effects need to be well controlled in the box-type bonding procedure.

After a successful explosive bonding, followed by machining to the required shape, the two halves of the shutter are welded together by electron beam welding with near full penetration. A specially designed groove near the welding edge helps prevent brittle intermetallic compounds from forming on the stainless-steel and GlidCop interface, as shown in fig. $3 b$.

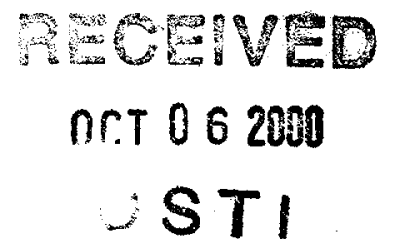




\section{High-heat-load applications}

In recent years, box-type explosively bonded units were used extensively for the APS new high-heat-load beamline components. Five different high-heat-load components have been designed and built using this new technique including V-shaped white beam photon shutters for undulator-only front ends and beamlines (fig. 4), white beam collimator for an x-ray compound diffraction lens (fig. 5), undulator white beam splitter (fig. 6), and an upgraded undulator white beam grazing-incidence knife-edge slit (fig. 7). All of these components are now operational in UHV condition.

Compared with the original APS undulator/wiggler-compatible photon shutter P1-20, the new designed $\mathrm{V}$-shaped photon shutter P2-30 provides $150 \%$ thermal loading capacity with more than $50 \%$ manufacturing cost savings. Similar to the $\mathrm{V}$-shaped photon shutter, we are designing a new V-shaped fixed mask for APS front end. Since in this design the photon beam will always impinged on the horizontally inclined surfaces, the V-shaped fixed mask provides higher thermal loading capacity, with the same grazingincidence angle and cooling method.

\section{Conclusion}

In recent years, special explosively bonded units with rectangular box-type joints were developed for the APS new high-heat-load beamline components. Based on this new technique, the box form of the GlidCop/stainless steel bonded component can first be built in two halves, then welded together to be UHV leak tight. This so called "half and half" process provides large design freedom for UHV high-heat-load component, so that we can built components with a complicated in-vacuum cooling surface geometry, such as a V-shaped cooling surface, which would be impossible with the traditional electric discharge manufacturing method. The single box-type structure can also be joined directly to a vacuum chamber. The undulator white beam grazing-incidence knifeedge slit (as shown in fig. 7) is one successful example.

Operation results show that box-type explosive bonding has provided reliable UHV leak-tight joints between GlidCop AL-15 and 304 stainless steel for APS high-heat-load beamline applications.

\section{Acknowledgements}

The authors would like to thank Mr. F. Carrera for help with the 3-D diagram preparation. This work was supported by the U.S. Department of Energy, Office of Science, under Contract No. W-31-109-Eng-38.

\section{References}

[1] GlidCop is a trademark of SCM Metal Products, Inc.

[2] G.R. Cowan et al., Met. Trans., 1971, vol.2, pp 3145-55.

[3] V. Shribman et al., Prod. Engr., Feb. 1969, pp 69-83.

[4] T.Z. Blazinski, Explosive Welding. Forming and Compaction. Applied Sciences Ltd., New York, London (1983), pp 189-343. 
[5] D. Shu, Y. Li. D. Ryding, T. M. Kuzay and D. Brasher, Rev.Sci.Instrum., 1995,66(2) p1783.

[6] T. Mochizuki, Y. Sakurai, D. Shu. T. M. Kuzay, and H. Kitamura, J. Synchrotron Rad. (1998) Vol.5. pl199-1201. 
Figure captions:

Fig. 1. The explosive bonding event.

Fig. 2. The explosive bonding wave morphology.

Fig. 3. (a) A typical rectangular box-type explosively bonded unit for one half of an APS photon shutter P2-30. (b) The bonding unit after machining to the required shape with a special designed groove near the welding edge.

Fig. 4. Photograph of the APS photon shutter P2-30.

Fig. 5. 3-D diagram of the white beam collimator for an x-ray compound diffraction lens at the APS beamline 3-ID.

Fig. 6. 3-D diagram of undulator white beam splitter for beamlines at the APS sector 4 .

Fig. 7. 3-D diagram of an upgraded undulator white beam grazing-incidence knife-edge slit for the APS beamline 2-ID. 


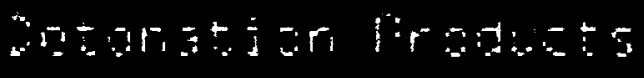

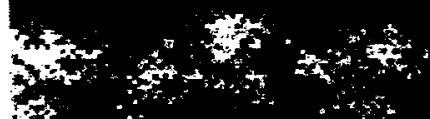

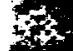

and

a 5 .

$x \sin x$ .

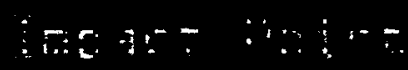

-
$\Xi-\because \because \because: \because:$

$+40+2$

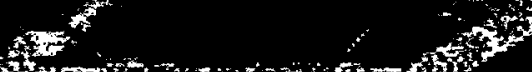
$(x+2)$ 45

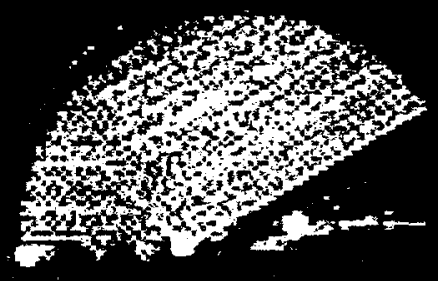




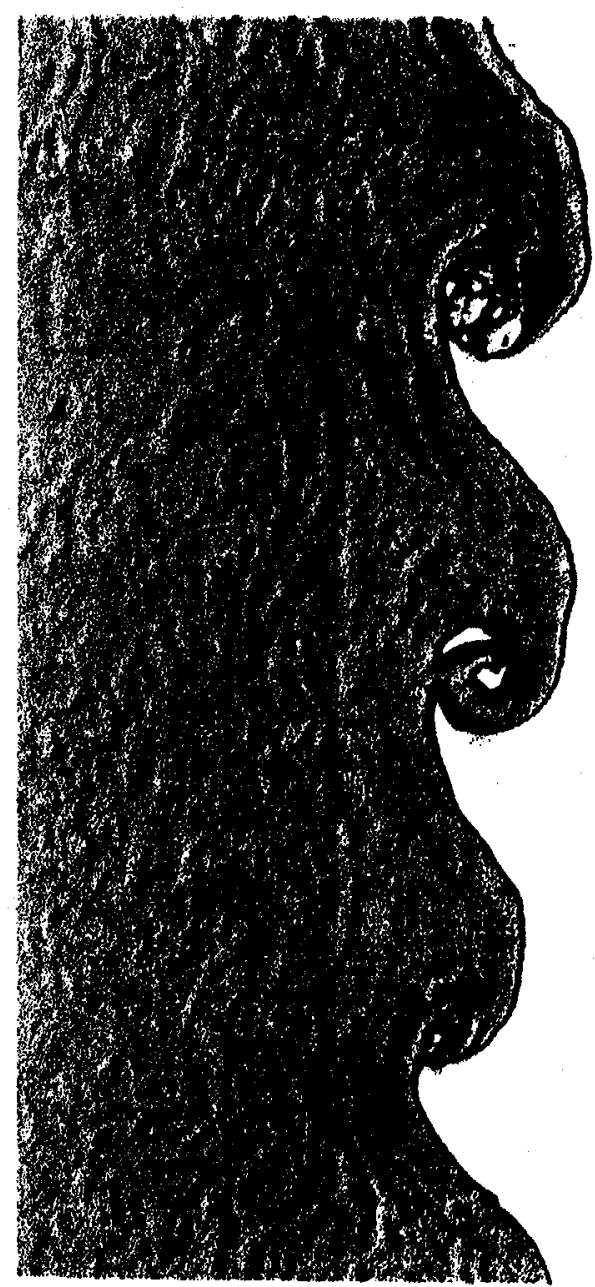


Fig. 3

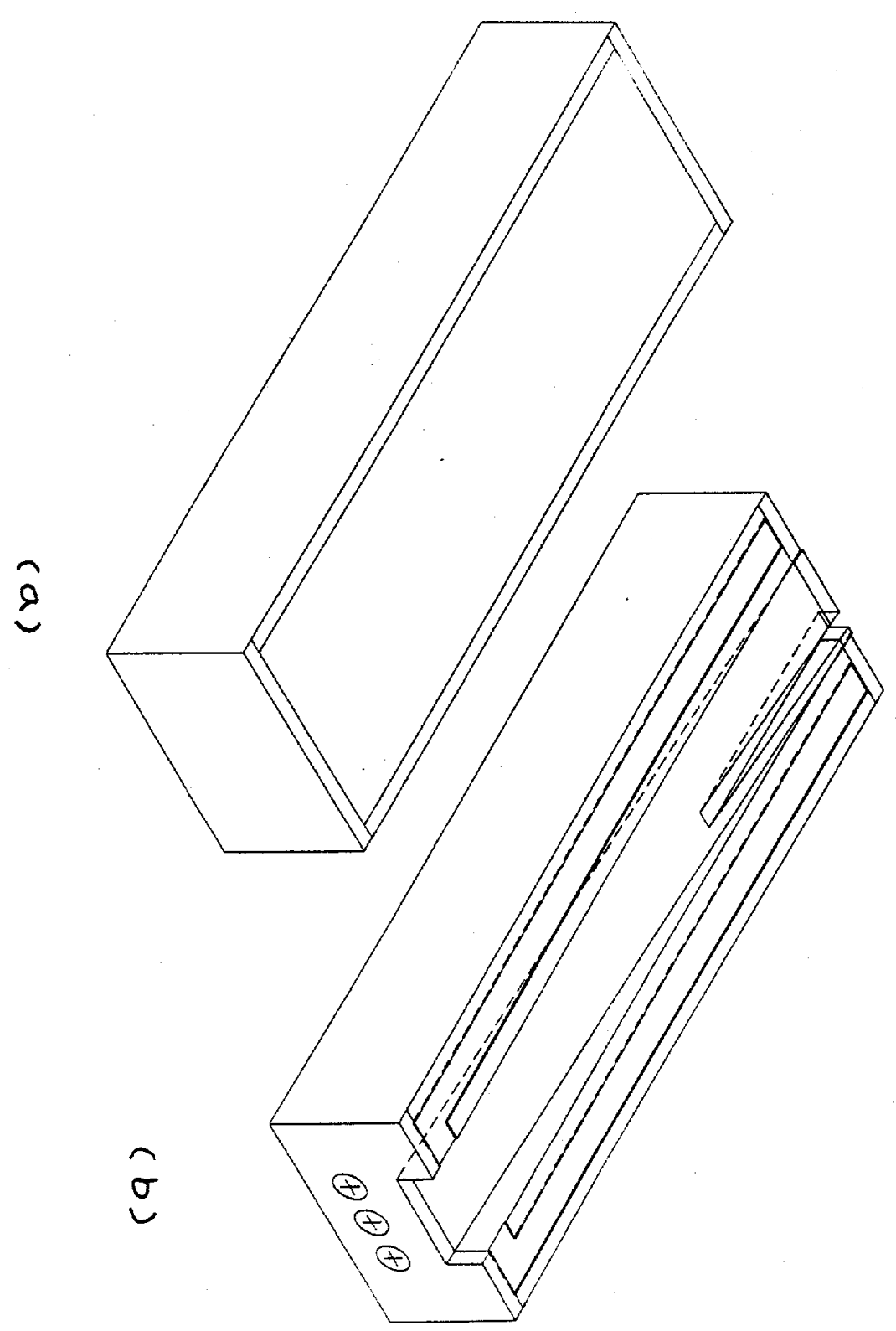


Fig. 4

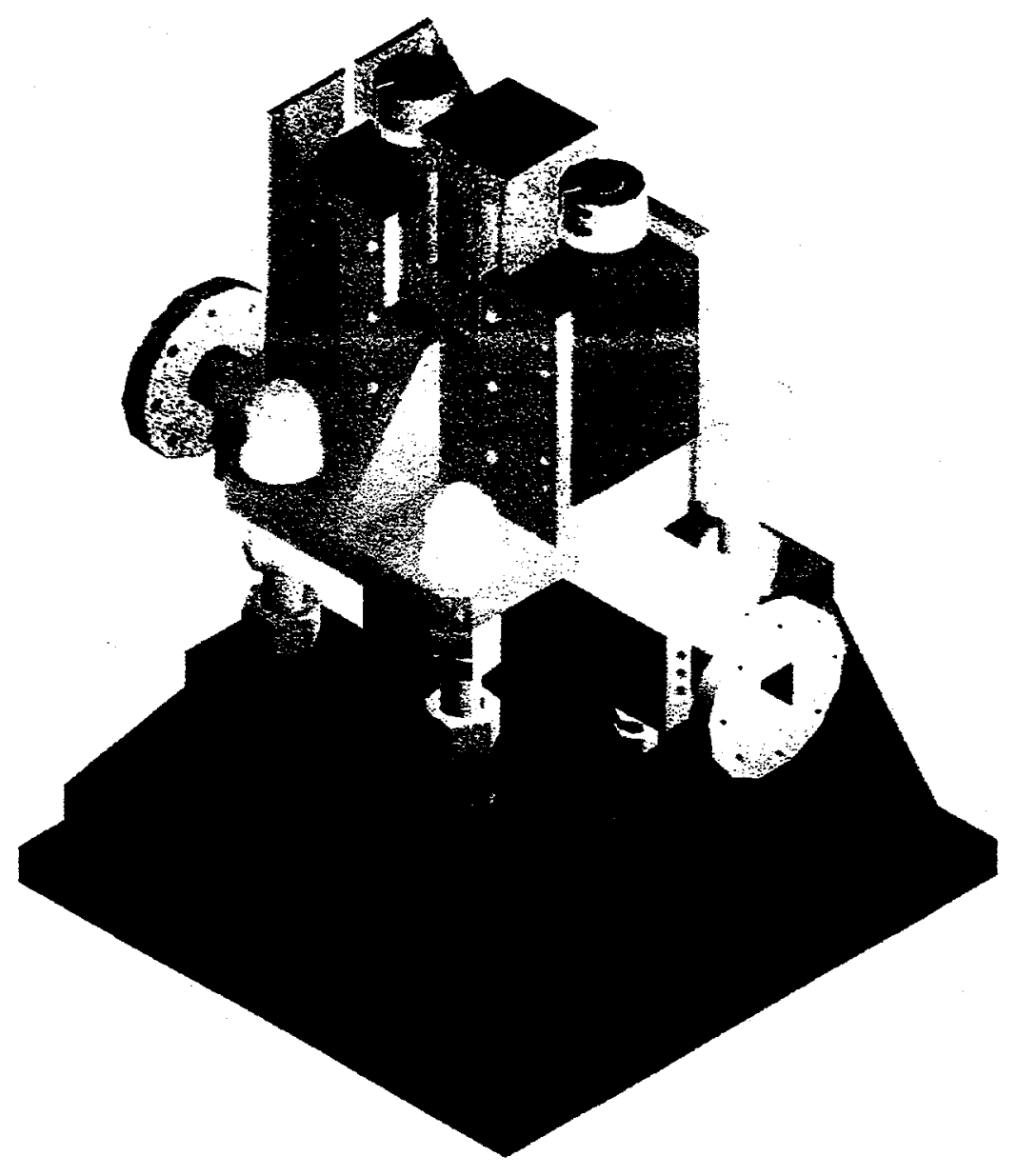




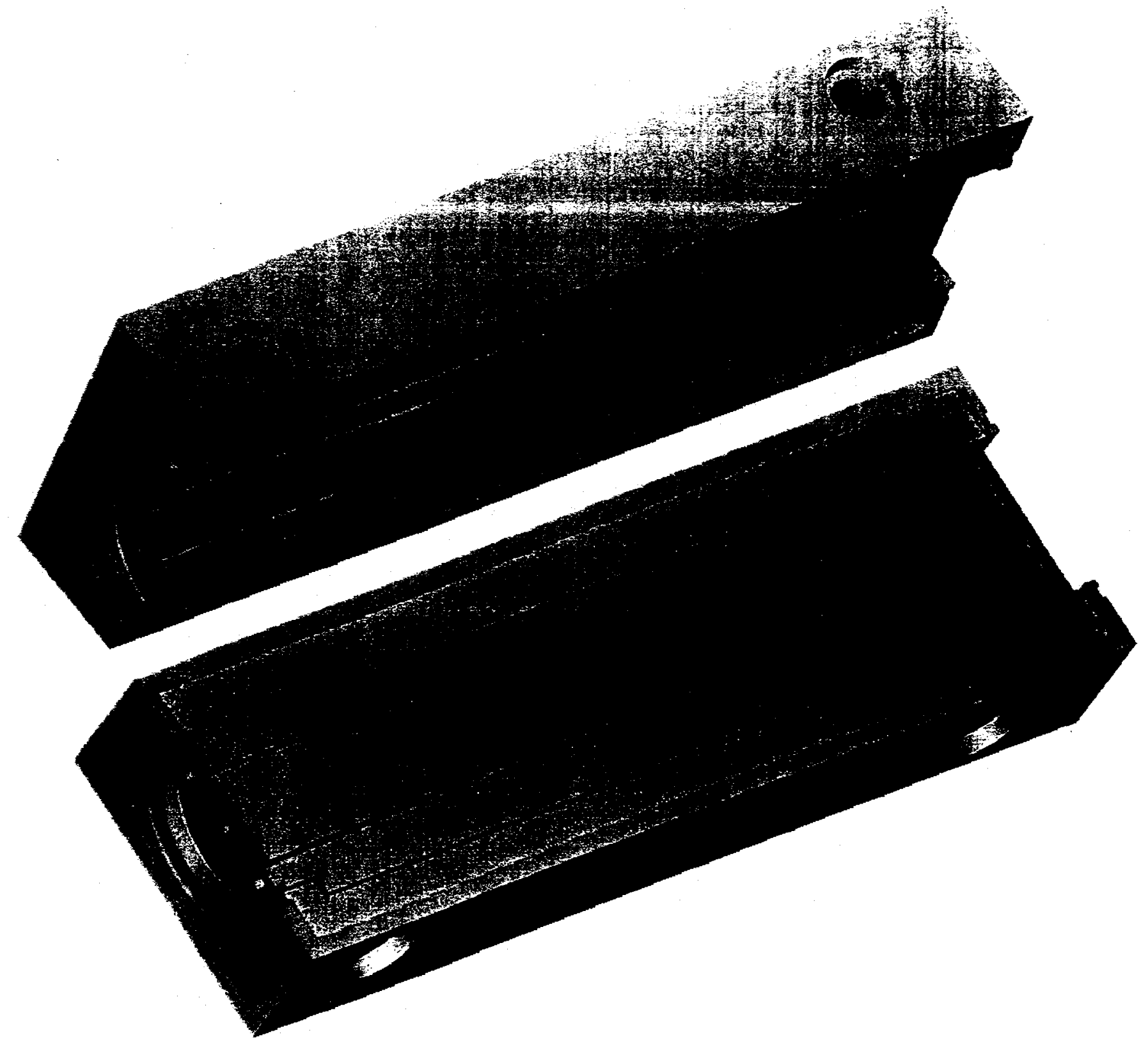

Fig. 5. 3-D diagram of the white beam collimator for an $\mathrm{x}$ ray compound diffraction lens at APS beamline 3-ID. 


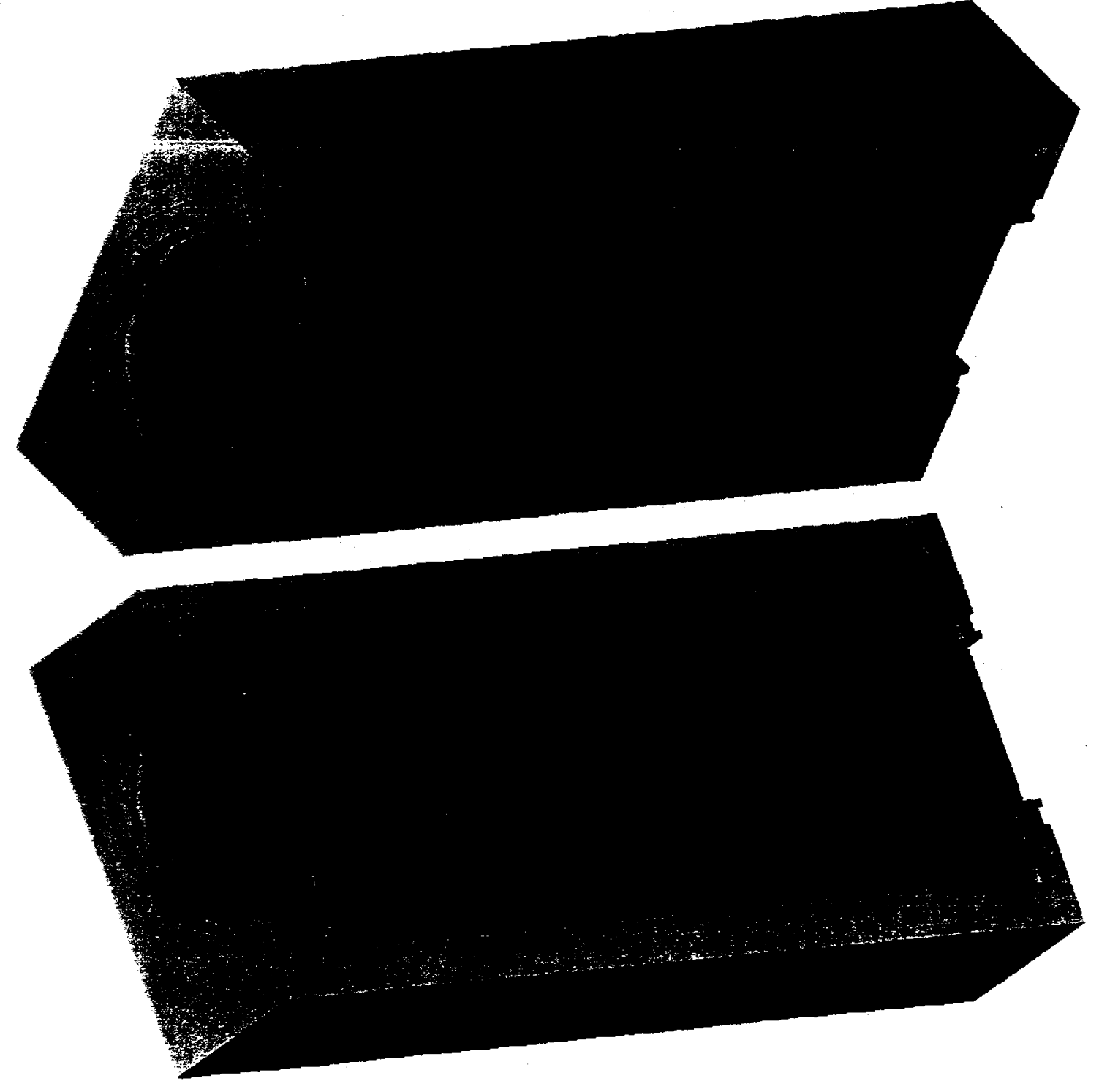

Fig. 6. 3-D diagram of undulator white beam splitter for beamlines at APS sector 4 . 


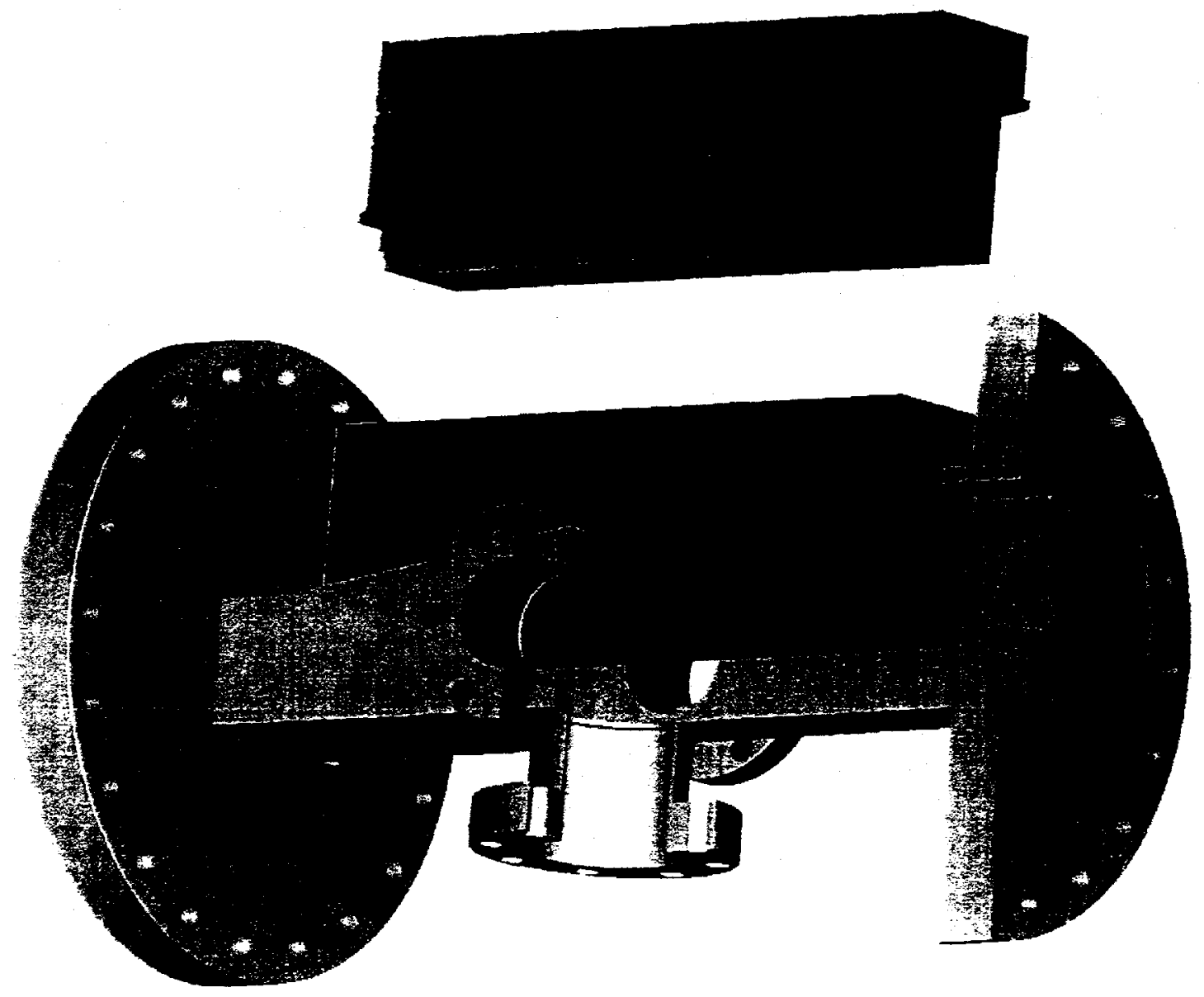

Fig. 7. 3-D diagram of an upgraded undulator white beam grazingincidence knife-edge slit for APS beamline 2-ID. 